Research Article

\title{
Classification of Building Damage Triggered by Earthquakes Using Decision Tree
}

\author{
Shaodan Li ${ }^{1}{ }^{1}$ and Hong Tang $\mathbb{D}^{2,3}$ \\ ${ }^{1}$ College of Resources and Environmental Sciences, Hebei Normal University, \\ Hebei Technology Innovation Center for Remote Sensing Identification of Environmental Change, Shijiazhuang 050024, China \\ ${ }^{2}$ State Key Laboratory of Remote Sensing Science, \\ Jointly Sponsored by Beijing Normal University and Institute of Remote Sensing and Digital Earth of Chinese Academy of \\ Sciences, Beijing 100875, China \\ ${ }^{3}$ Beijing Key Laboratory for Remote Sensing of Environment and Digital Cities, Faculty of Geographical Science, \\ Beijing Normal University, Beijing 100875, China
}

Correspondence should be addressed to Hong Tang; hongtang@bnu.edu.cn

Received 19 April 2020; Revised 18 June 2020; Accepted 7 July 2020; Published 31 July 2020

Academic Editor: Paolo Lonetti

Copyright ( 2020 Shaodan Li and Hong Tang. This is an open access article distributed under the Creative Commons Attribution License, which permits unrestricted use, distribution, and reproduction in any medium, provided the original work is properly cited.

Field survey is a labour-intensive way to objectively evaluate the grade of building damage triggered by earthquakes. In this paper, we present a decision-tree-based approach to classify the type of building damage by using multiple-source remote sensing from both pre- and postearthquakes. Specifically, the boundary of buildings is delineated from preearthquake multiple-source satellite images using an unsupervised learning method. Then, building damage is classified into four types using decision tree method from postearthquake UAV images, that is, basically intact buildings, slightly damaged buildings, partially collapsed buildings, and completely collapsed buildings. Furthermore, the slightly damaged buildings are determined by the detected roof-holes using joint color and height features. Two experimental areas from Wenchuan and Ya'an earthquakes are used to verify the proposed method.

\section{Introduction}

A major reason for mortality in an earthquake might be the damaged buildings. The amount and grade of building damage are essential information for rescue and recovery, and they stress the importance of a rapid and reliable detection of damaged areas. For the masonry and reinforced buildings, the European Macroseismic Scale 1998 (EMS98) listed five kinds of damage grades coupled with a detailed description, that is, slight damage, moderate damage, heavy damage, very heavy damage, and destruction, and each grade gives a clear description of building damage [1]. As we know, the grade of building damage can be accurately evaluated according to field survey. However, field survey is a labour-intensive way to objectively evaluate the grade of building damage triggered by earthquakes. Fortunately, with the rapid development of spatial information technology, remote sensing imagery has become a very important way to identify and assess the damaged buildings in hard-hit areas. Recently, both satellite and aerial images have been used to detect earthquake-induced building damage because of the high spatial resolution and relatively low cost $[2,3]$. Different from the field survey, remote sensing imagery provides the central projection of the buildings from the hawkeye view, that is, roof information. Therefore the walls of buildings are difficult to detect from the satellite images. For example, if there are some cracks in the walls, they cannot be detected with satellite images. Therefore, the building damage classification based on remote sensing imagery is difficult to reach the same level of the accuracy as field survey. It is also difficult to construct an explicit correspondence between the building damage grades (e.g., from EMS98) and their appearance in remote sensing imagery.

In order to achieve satisfactory result in building damage detection, various damage grading schemes have been 
defined according to the type of the remote sensing imagery. For instance, LiDAR data can detect many specific damage types [4], such as incline plane, heap of debris, and pancake collapses. However, in this paper, more attention would be paid to how to identify different building damage types using satellite or airplane images. According to different methods and different resolution, the damage category detected from satellite imagery can be divided into three cases: (1) The first is two grades. Saito et al. visually interpreted collapsed buildings using pre- and postseismic IKONOS images of the 2001 Gujarat earthquake [5]. Gusella et al. proposed an object-based method to quantify collapsed buildings using QuickBird images taken before and after the Bam earthquake, and an overall accuracy of $70.5 \%$ was obtained by this method [6]. Li et al. presented a method using both spectral and spatial information of QuickBird imagery to detect damaged buildings in the 2008 Wenchuan earthquake [7]. The combination of spectral and spatial features produced a better outcome compared with using spectral information alone. (2) The second is three grades. Liu et al. proposed an automatic method to detect undamaged, slightly damaged, and collapsed buildings using the regional structure and texture information from postevent IKONOS images of Bhuj earthquake [8]. Gamba et al. detected undamaged, partly collapsed, and totally collapsed buildings by comparing the normalized difference vegetation index (NDVI) and linear segments of buildings in pre- and postevent images of Tsunami earthquake [9]. Tong et al. take DSMs created from pre- and postseismic IKONOS stereo image pairs to detect noncollapsed, half-collapsed, and totally collapsed buildings of Wenchuan earthquake from both building and block levels [10]. (3) The third is more than three grades. Chesnel et al. proposed a method based on analysis of building roofs in pre- and postevent QuickBird images to detect the damaged buildings, and they used EMS98 damage scale as a reference scale [11]. Since it is difficult to detect Grade 1 and Grade 2, only intact Grade 3, Grade 4, and Grade 5 are retained. Iwasaki and Yamazaki detected mid-story collapsed buildings based on their height change estimated from shadow lengths in pre- and postevent QuickBird images, and the building damage was classified into four levels: totally collapsed (Grade 5), partially collapsed (Grade 4), surrounded by debris (Grade 3), and combined Grade 1 and Grade 2; the EMS98 damage scale is taken as a reference scale [12]. Yamazaki et al. proposed a context-based damage detection approach using a combination of edge textures, spatial relationship, and multispectral gray tone, and three damage scales are classified according to the ratio between the debris area and the building object: none $(<25 \%)$, light (25\% 50\%), and moderate (>50\%) [13].

In general, heavy damage grades such as totally collapsed category can be detected with the satellite imagery. Identification of lower damage grades remains a challenge, even with submeter resolution remote sensing data [2]. As an indispensable supplement for the satellite imagery, the UAV images can make up for the lack of satellite images in a certain extent. On one hand, the UAV imagery has significant improvement of the spatial resolution to determine the damage for a single building, which can reach the centimeter. On the other hand, 3D point clouds of the hit areas can be reconstructed based on the higher overlapping from the original UAV images $[14,15]$.

A popular method to acquire building damage information using both pre- and postearthquake remote sensing data is change detection. Change detection approaches, including image enhancement [16] and postclassification comparison [17], identify the differences in the state of a building by observing it at different times. However, an unsupervised way is presented to detect building damage using both pre- and postearthquake remote sensing data in this paper. Specifically, at first, an unsupervised classification framework for rapid building mapping after earthquakes from preearthquake multiple heterogeneous VHR satellite images is presented, which could eliminate the need to finetune model parameters from one image to another. Then, the building damage is detected and classified into four types (i.e., basically intact buildings, slightly damaged buildings, partially collapsed buildings, and completely collapsed buildings) using decision tree method from postearthquake UAV images.

The remainder of this paper is organized as follows. In Section 2, the study area is introduced. In Section 3, the proposed method for rapid building detection from preearthquake heterogeneous satellite images and building damage classification from postearthquake UAV images is presented in detail. In Section 4, the experimental results are described. Finally, the discussion is drawn in Section 5.

\section{Study Area}

In this paper, there are two study areas, Yuxi village in Ya'an City and Zhoujiawan village in Hanwang town, as shown in Figure 1(a). Ya'an, located in the center of Sichuan in China, experienced the Ya'an earthquake with a magnitude of 7.0 on 20 April 2013. The maximum intensity of the Ya'an earthquake is IX degrees. The first study area, Yuxi village, is one of the areas most affected by the earthquake.

Hanwang town, also located in Sichuan province, experienced the Wenchuan earthquake with magnitude of 8.0 on 12 May 2008. The maximum intensity of the Wenchuan earthquake is XI degrees, and the earthquake caused huge casualties and property losses. The second study area, Zhoujiawan village, is located in the junction of IX-degree and $\mathrm{X}$-degree intensity zone, and the building damage is more serious. Both of the two earthquakes are located in the Longmenshan fault zone.

\section{Method}

3.1. Experimental Data. Preearthquake VHR satellite images and the corresponding postearthquake UAV images that covered the two study areas were obtained in this paper. Firstly, two preearthquake VHR satellite images that covered two study areas were used for building extraction, as shown in Figure 1(b). One image of an area in the Zhoujiawan village of Hanwang town was taken by the QuickBird satellite on 29 February 2008 , with a size of $6500 \times 6500$ pixels. Another image of Yuxi village of Ya'an city was acquired on 


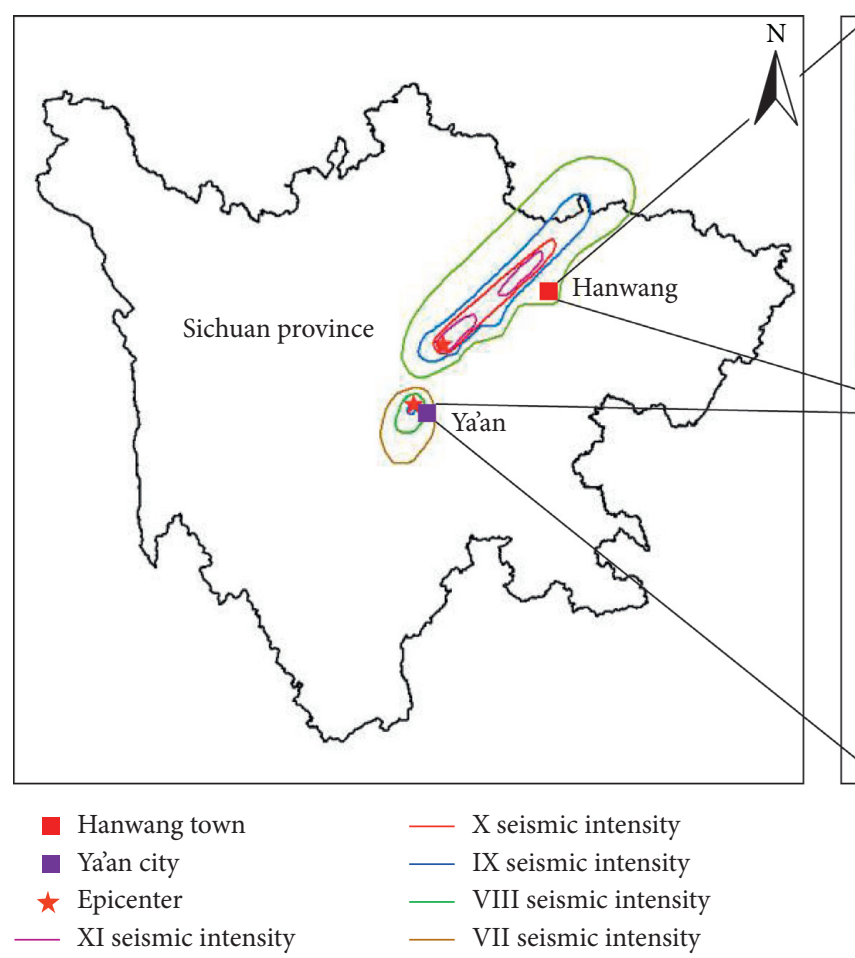

(a)

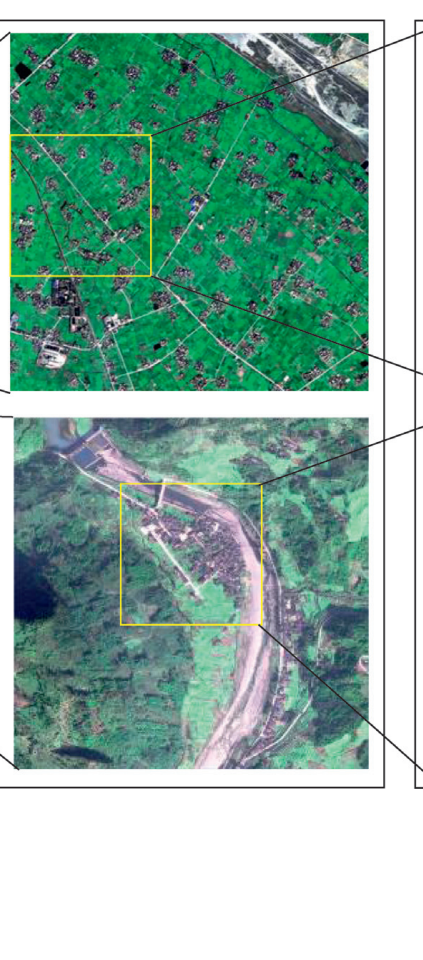

(b)

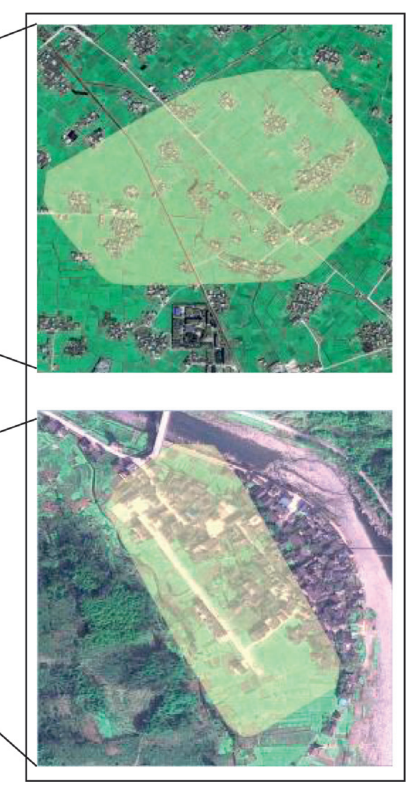

(c)

Figure 1: Two study areas and preearthquake satellite images. (a) Geographical location of two study areas; (b) two preearthquake satellite images; (c) the magnified regions that were covered by postearthquake UAV images.

22 January 2013 by the Pléiades satellite, with a size of $8000 \times 8000$ pixels. Figure $1(\mathrm{c})$ shows the magnified regions that were covered by postearthquake UAV images.

Secondly, two postearthquake UAV images that covered two study areas were used for building damage classification, as shown in Figure 2(b). After Ya'an earthquake, a total of 93 UAV images covering Yuxi village were obtained by the eight-rotor UAV with Canon 5DMARK? on 24 April, and the spatial resolution of UAV images is about $2.5 \mathrm{~cm}$. After Wenchuan earthquake, a total of 151 postearthquake UAV images covering Zhoujiawan village were obtained on 29 May 2009, and the average ground spatial distance (GSD) is about $7.9 \mathrm{~cm}$. For the postearthquake UAV images of two study areas, they were preprocessed with the Pix4UAV commercial software, and the orthomosaic images and 3D point clouds were derived by the Pix4UAV software. The point clouds contain height information and color information, that is, red, green, and blue. The average point densities of the point clouds in Zhoujiawan village and Yuxi village are 190 points $/ \mathrm{m}^{2}$ and 290 points $/ \mathrm{m}^{2}$, respectively.

\subsection{Building Extraction from Preearthquake VHR Satellite} Images. In this section, the proposed method of building damage classification using decision tree algorithm is presented. As shown in Figure 3, the building boundary is firstly extracted from preearthquake heterogeneous VHR satellite images. Within the boundaries of buildings, building damage information is classified into four types using the orthomosaic image and 3D point clouds derived from postearthquake UAV images, and the types include basically intact buildings, slightly damaged buildings, partially collapsed buildings, and completely collapsed buildings.

Before the building damage detection, building boundary needs to be extracted. In this subsection, an unsupervised method for rapid building mapping from preearthquake VHR satellite images is proposed, which could eliminate the need to fine-tune model parameters from one image to another. The proposed method of building extraction, which was called "gCRF_MBI" [18], consists of three sequential steps: (1) detection of built-up area candidates (BACs) from preearthquake satellite images, (2) extraction of the morphological features (MFs) masked by the BACs, and (3) unsupervised classification of both buildings and nonbuildings. The flowchart of building extraction from preearthquake satellite images is shown in Figure 4.

Step 1. BACs detection: The BACs are detected using spectral residual (SR) method from preearthquake satellite image. Firstly, the saliency map is derived from preearthquake satellite image using spectral residual method, and then the corresponding binary map with BACs is generated using a selection threshold [19]. The BACs are taken as basic units for feature extraction and unsupervised classification.

Step 2. MFs extraction: The morphological building index (MBI) is employed to extract morphological features of buildings from preearthquake satellite image [20]. The morphological features (MFs) of buildings 


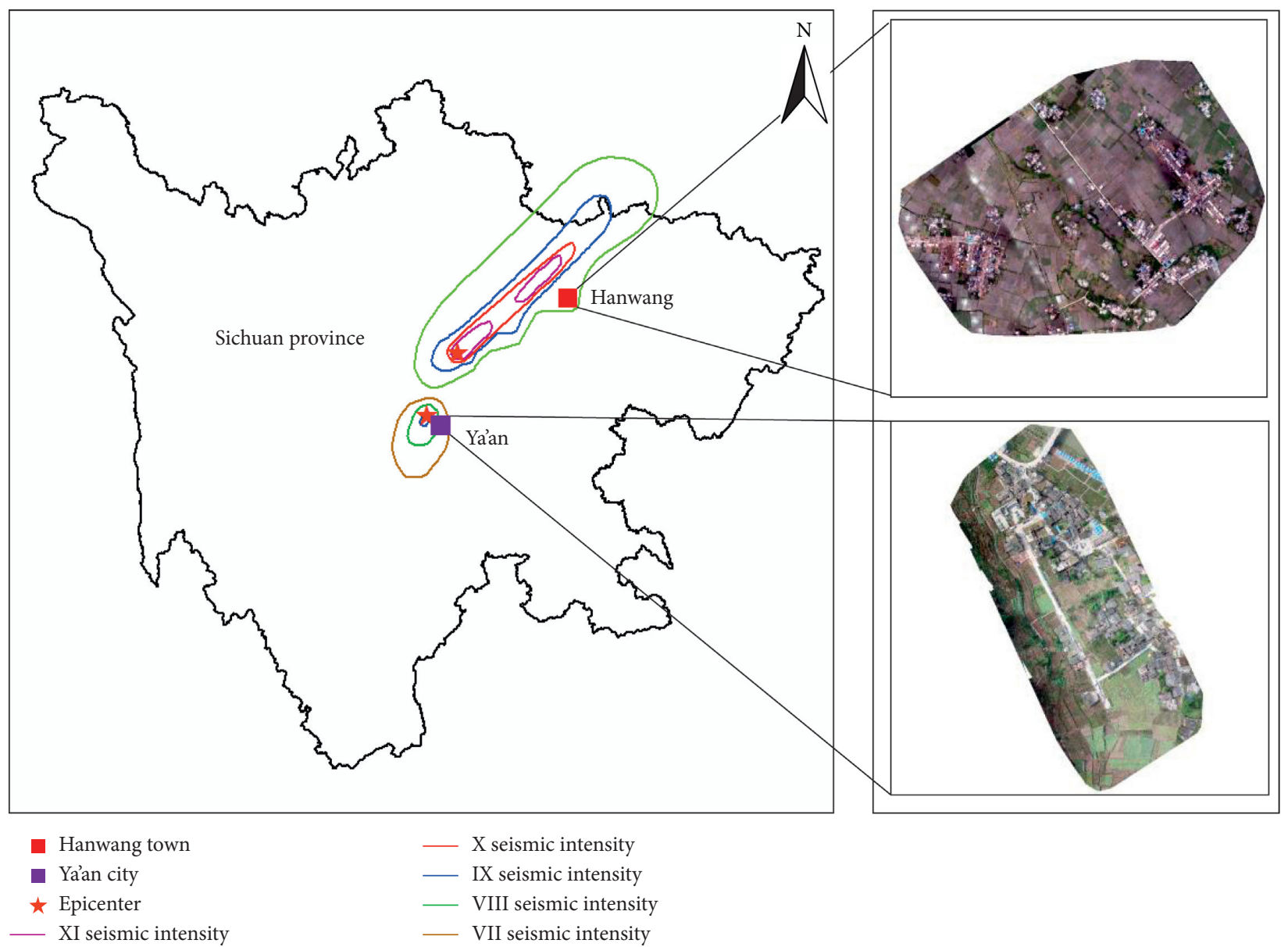

(a)

(b)

FIgURE 2: Two study areas and postearthquake UAV images. (a) Geographical location of the two study areas; (b) two postearthquake UAV images in Zhoujiawan village and Yuxi village.

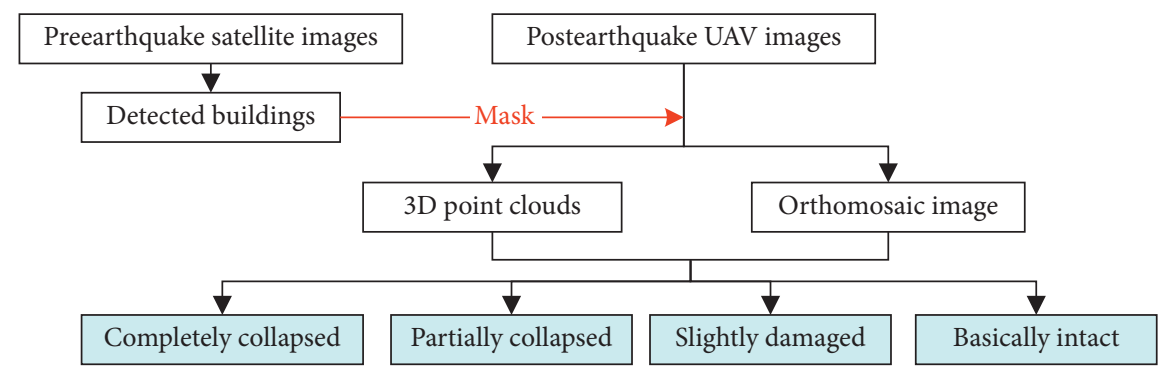

FIGURE 3: Flowchart of building damage classification.

within the BACs are extracted using the MBI algorithm, and this feature image with morphological features of buildings is called MBI image here.

Step 3. Building extraction: Based on the BACs, the generalized Chinese restaurant franchise (gCRF) model is expanded to fuse both panchromatic (PAN) image and $\mathrm{MBI}$ feature image for unsupervised learning and classification [21]. To simplify the description, PAN and $\mathrm{MBI}$ images are used as inputs to the gCRF model for two-level hierarchical clustering, which are local clustering and global clustering, respectively. In the global clustering, only buildings and nonbuildings are assumed. Since the morphological features imply the structural information of buildings, buildings can be identified with larger averaged MBI values.

In the earthquake disasters, multiple preearthquake satellite images might be available in a progressive way. The proposed method could also be utilized in this situation. For the sake of the simplification of description, we take two images from different sensors as an example to describe the algorithm for this situation: one image is available after the other one. It is assumed that the two images come from two 


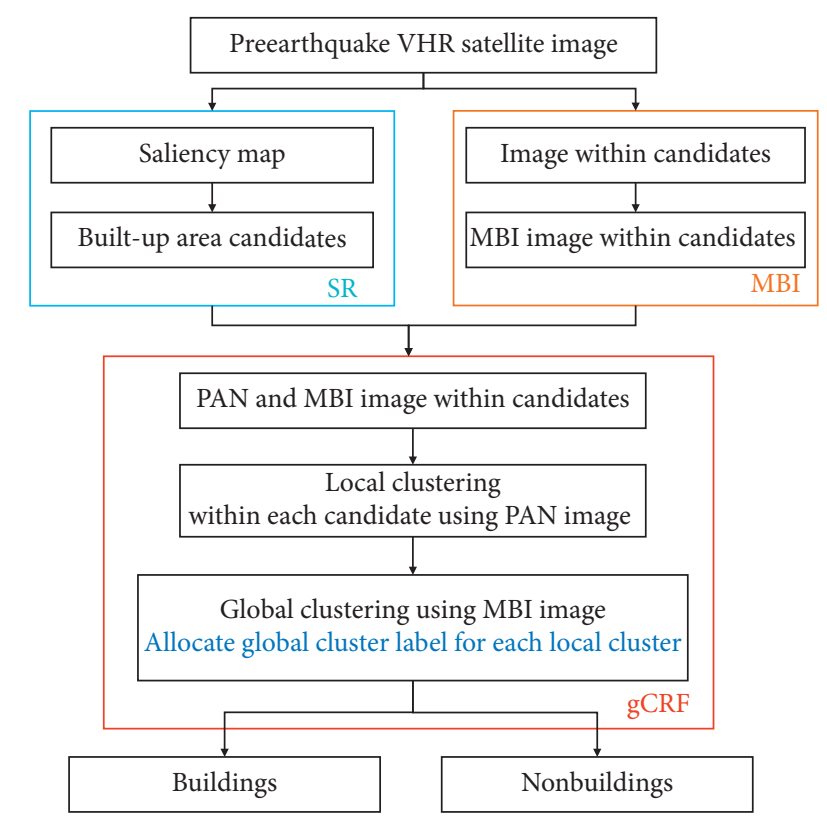

FIGURE 4: Flowchart of building detection from preearthquake satellite image.

different sensors, that is, QuickBird and Pléiades. Therefore, we could learn statistical models of global clusters from QuickBird image. Given a new Pléiades image, the clustering process consists of (1) local clustering using Pléiades panchromatic image and (2) allocating the global cluster label for each inferred local cluster within each candidate using the learned statistics model of global clusters. More details on building detection from heterogeneous satellite images can be found in previous study [18].

3.3. Building Damage Classification Using Decision Tree Algorithm. Compared with satellite images, UAV images have two obvious advantages: First, they have higher spatial resolution, which has rich spatial details, clear geometric feature, and clear texture. Second, the UAV images have higher overlapping. 3D point cloud data can be reconstructed based on the higher overlapping from the original UAV images. It is exciting that point cloud data contain the morphological features of buildings, such as the height of buildings.

According to spectral feature of UAV images and morphological feature of the reconstructed point cloud data from the UAV images, combined with the existing building damage classification standards, building damage from postearthquake UAV images is classified into four types: basically intact buildings, slightly damaged buildings, partially collapsed buildings, and completely collapsed buildings. Within the building boundary, building damage will be detected using decision tree algorithm from postearthquake UAV images. In this section, the spectral and morphological features of four types in the UAV images are first described. Then, classification features are extracted from postearthquake UAV image. Finally, the decision tree algorithm for building damage classification is presented.
3.3.1. Characteristic Description of Building Damage in UAV Images. Since building damage classification from UAV images is different from the standard building damage grades (e.g., from EMS98), spectral and morphological features of four building damage types in this paper are first described, and we refer the reader to [22].

(1) Basically Intact Buildings. Spectral features: the roof of the buildings is intact, the distribution of brightness is clear, and the hue is regular. The texture of the roof is clear and arranged in order.

Morphological features: the buildings have clear boundaries and geometric shapes, and no rubble was accumulated around the buildings. The 3D models of the buildings were complete, and the average height of the buildings in the point cloud approximates the general height.

(2) Slightly Damaged Buildings. In fact, there are many types of slightly damaged buildings; for example, there are cracks in the walls, wall skin falls off, and tiles fall from the roofs; and these types cannot be detected from remote sensing images. The case of tiles that fell from the roofs is the most easily detected from the image. Therefore, the slightly damaged buildings refer to the case where tiles fell from the roofs in this paper, which is called "roof-holes."

Spectral features: the roof of the buildings is basically intact, and the texture is arranged in disorder. The distribution of brightness has good homogeneity. However, the brightness of the roof-holes becomes darker than its surroundings.

Morphological features: the geometric boundary of the building is clear, but a few tiles fell from the roof. Since only a few tiles fell off, the average height of the buildings is similar to that of basically intact buildings. The $3 \mathrm{D}$ model is approximately completed, as shown in Figure 5(b). However, the height of the roof-holes is slightly lower than its surroundings shown in its $3 \mathrm{D}$ point clouds.

(3) Partially Collapsed Buildings. Spectral features: for the partially collapsed buildings, there are collapsed part and noncollapsed part. The collapsed part of the roofs shows black and messy spots in the images. The regularity of the texture in the collapsed area is destroyed, and the regularity of the texture of roof is destroyed. For the noncollapsed part of the roofs, the spectral feature is similar to that of the basically intact buildings.

Morphological features: the boundary of the buildings disappears, and the buildings do not have totally geometric shapes and linear texture. The roof of the buildings is partially collapsed. In the $3 \mathrm{D}$ point clouds, the average height of noncollapsed part of the buildings is still similar to that of the basically intact buildings. However, the average height of the collapsed part is much lower than that of the noncollapsed part, as shown in Figure 5(c). Therefore, the variance of the height of the buildings is larger than that of basically intact buildings.

(4) Completely Collapsed Buildings. Spectral features: the completely collapsed buildings show black and messy spots in the images. The texture of the buildings was arranged in 

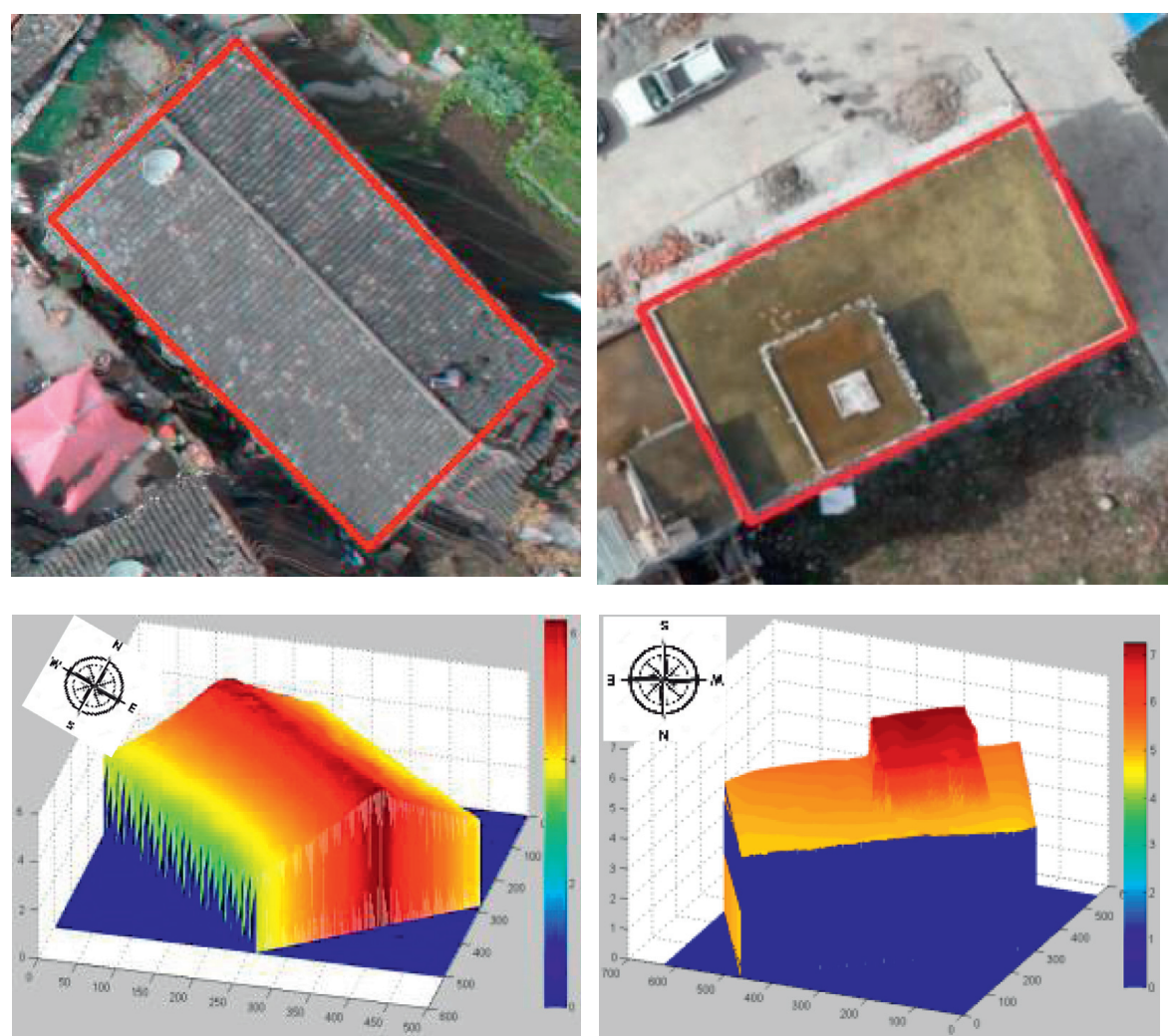

(a)


(b)

Figure 5: Continued. 

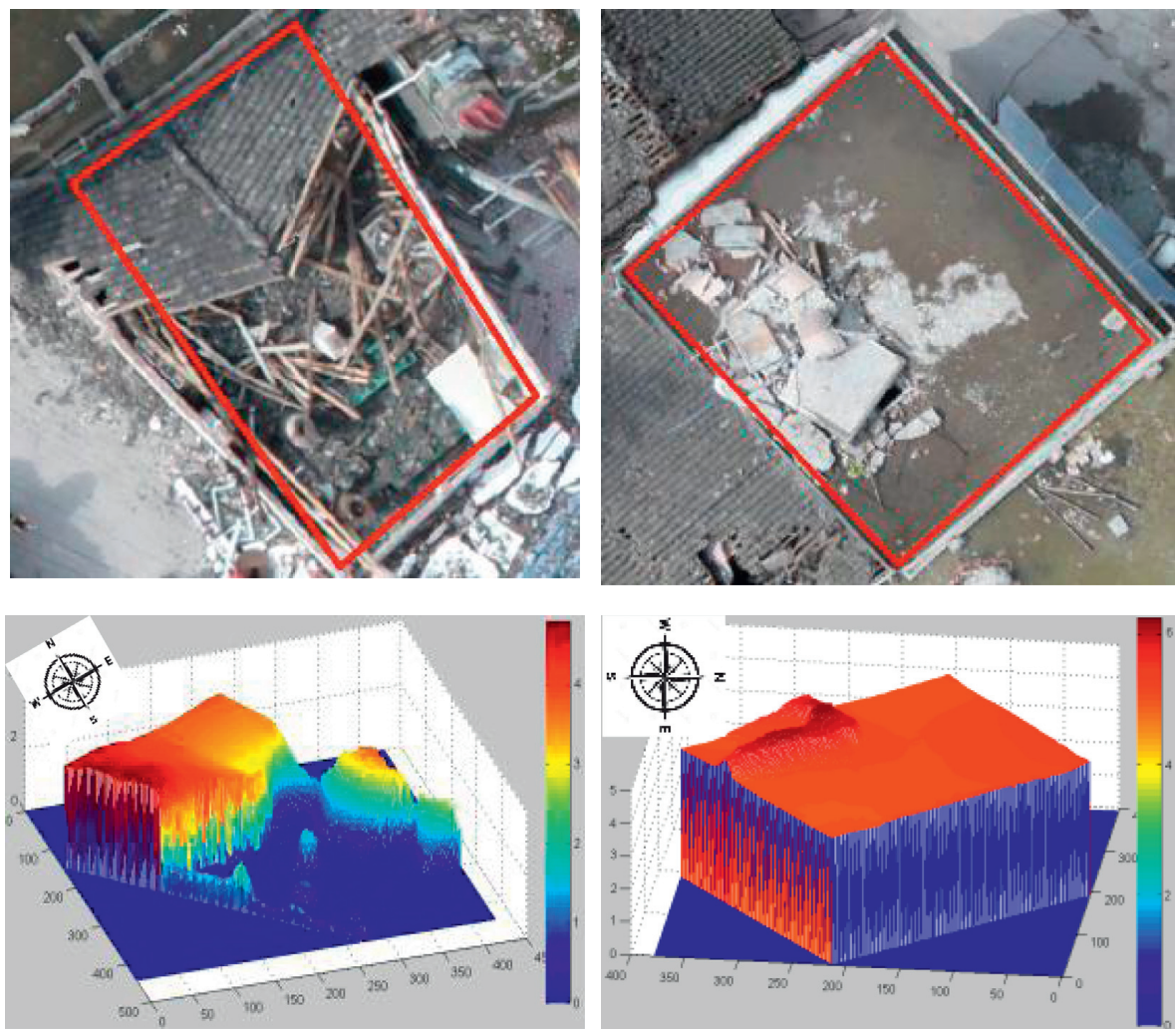

(c)
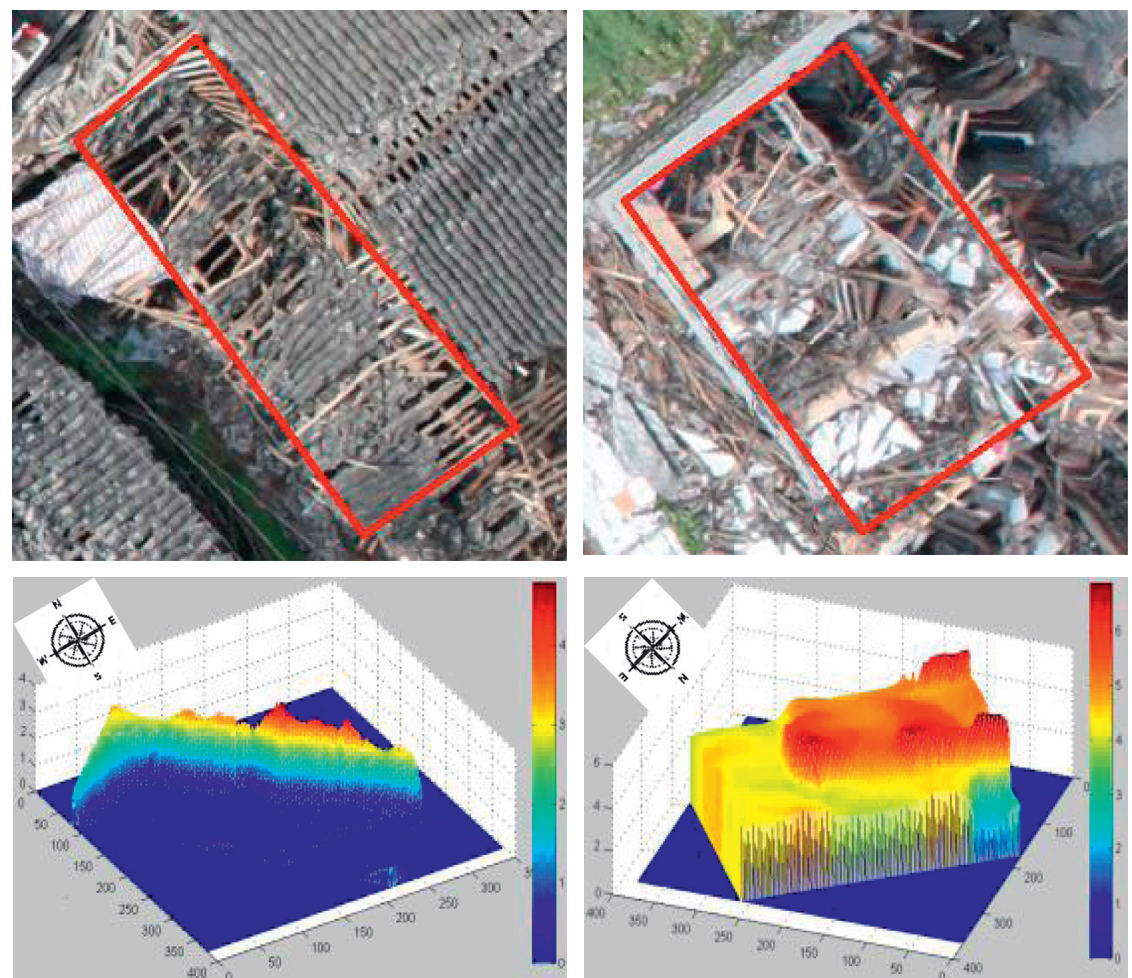

(d)

FIGURE 5: UAV images and the corresponding 3D models for four building damage types. (a) Basically intact buildings; (b) slightly damaged buildings; (c) partially collapsed buildings; (d) completely collapsed buildings. 
disorder, and the regularity of the texture was destroyed. The spectral feature of the completely collapsed buildings is similar to that of the collapsed part of partially collapsed buildings.

Morphological features: the boundary of the buildings disappears, and the buildings do not have totally geometric shapes. The roof of the buildings was completely collapsed, and a lot of rubble was accumulated around the buildings. In the 3D model, the average height of buildings is much lower than that of basically intact buildings, as shown in Figure 5(d).

3.3.2. Feature Extraction. Generally, the characteristics of the buildings in the remote sensing imagery are color, texture, geometric shape, and height. In order to interpret building damage class, the first is to find the most obvious image feature that could distinguish some damage class from others. In this paper, height information of buildings from 3D point clouds and the "roof-holes" detected using joint spectral and shape features from the postearthquake UAV images are employed to conduct building damage classification.

(1) Height Information of Buildings. The UAV images have very high spatial resolution, clear texture, and rich spatial details, which represent the obvious advantage for visual interpretation. Due to the abundance of spatial details in the UAV images, the buildings often have complex spectral information, and this leads to the phenomenon of "the same object with different spectrum." Therefore, the result is not satisfactory if building damage classification is identified only based on spectral information in the UAV images. Fortunately, 3D point clouds reconstructed by the UAV images can complement the drawback. Since the height of buildings is a significant feature in determining the building damage, the judgment of the building damage classification is mainly dependent on the height information of the buildings.

In order to obtain the height of each building, 3D point clouds of each building are first extracted based on the boundary of each building. Then, 3D model of each building is reconstructed according to point clouds of each building. When the buildings were damaged due to the earthquake, the height of buildings would be changed. The change in the height of buildings could be measured by the variables of average and variance of the height. Based on the degree of change of the two variables, it is possible to determine the types of building damage, such as complete collapse, partial collapse, or noncollapse. Therefore, the average and variance of the height of buildings are the significant features in determining the building damage types.

(2) Roof-Hole Detection. For the noncollapsed buildings, it is difficult to make a distinction between slightly damaged buildings and basically intact buildings only using the height of buildings. The roof-holes can be used to identify slightly damaged buildings from basically intact buildings. The socalled "roof-hole" is detected using the Chinese restaurant franchise (CRF) model, a construction method on the hierarchical Dirichlet process. The flowchart of roof-hole detection is shown in Figure 6. The method of roof-hole detection consists of three steps, described as follows:

Step 1. Data preprocessing: The postearthquake UAV images are first processed to get orthomosaic image and gradient image, which are the input of the CRF model. The Pix4UAV software [23] is used to produce the orthomosaic image and 3D point clouds, and 3D point clouds are further processed, which produces DSM, DEM, nDSM, and the gradient image.

Step 2. CRF model: The CRF model, which could fuse two different features, is employed to detect the roofholes. To simplify the description, the UAV image with joint color and shape features could be explained as the customer. In the metaphor of the CRF, two random processes occur when a customer enters the restaurant: (1) the customer randomly chooses to either sit at an existing table or start a new table according to the UAV image with joint color and shape features; (2) customers who sat at a table randomly select a dish to eat based on the UAV images. From the perspective of image processing, both table selection and dish selection correspond to local clustering and global clustering.

Step 3. KL divergence: The roof-holes are finally detected based on the CRF clustering result. In this case, it is done by comparing the distribution of the clustering result and the distribution of its ground truth. The similarity between two distributions is calculated based on Kullback-Leibler (KL) divergence. The most representative with high scores can be selected as the detected roof-holes. More details on roof-hole detection can be found in previous study [24].

3.3.3. Decision Tree Method. Based on building features extracted from the postearthquake UAV images, decision tree method is used to classify the building damage. Decision tree methods have long been used in machine learning and pattern recognition as efficient multilabel classifiers. Generally, a decision tree contains a root node, several internal nodes, and several leaf nodes. The leaf nodes correspond to the classification results, and the classification results correspond to the building damage types in this paper, that is, basically intact buildings, slightly damaged buildings, partially collapsed buildings, and completely collapsed buildings. Each of the internal nodes corresponds to an attribute test. The sample set contained in each node is divided into child nodes according to the results of the attribute test. The root node contains the full samples. The path from the root node to each leaf node corresponds to a decision test sequence.

It is noticed that the decision tree used in this paper does not need to conduct the attribute selection. The splitting attributes are deterministic in this paper, which are the average and variance of the height of buildings and detected roof-holes, and the order of the splitting attributes is also 


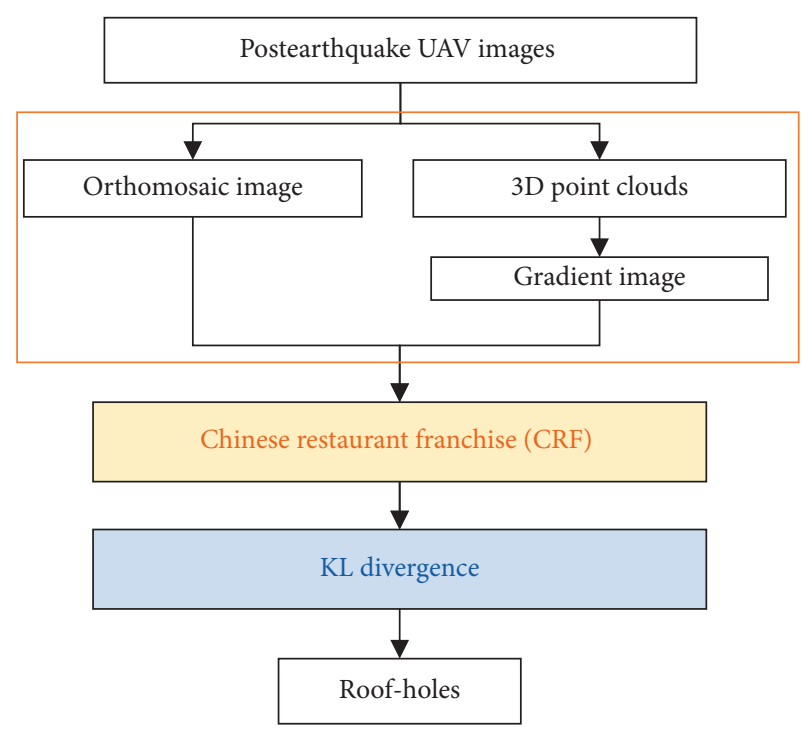

FIGURE 6: Flowchart of the roof-hole detection.

determined. In this decision tree, what we need to do is to choose the appropriate thresholds for the average and variance of the height of buildings, and the thresholds are determined as follows [25].

Given sample set $D$ and the attribute $a$, assume that $a$ has $n$ different values on $D$, sorting these values from small to large, as $\left\{a^{1}, a^{2}, \ldots, a^{n}\right\}$.

$$
\begin{aligned}
T_{a}= & \left\{\frac{a^{i}+a^{i+1}}{2} \mid 1 \leq i \leq n-1\right\}, \\
\operatorname{Gain}(D, a)= & \max _{t \in T_{a}} \operatorname{Gain}(D, a, t)=\max _{t \in T_{a}} \operatorname{Ent}(D) \\
& -\sum_{\lambda \in\{-,+\}} \frac{\left|D_{t}^{\lambda}\right|}{|D|} \operatorname{Ent}\left(D_{t}^{\lambda}\right),
\end{aligned}
$$

where Ent $(D)$ is the information entropy of the current sample set $D$. Gain $(D, a, t)$ is the information gain of the sample set $D$ based on the division point $t$. Therefore the division point that maximizes Gain $(D, a, t)$ can be selected as the threshold of the attribute.

In this decision tree, the splitting attributes include the average of the height of the building, the variance of the height, and the detected roof-holes. The flowchart of decision tree is shown in Figure 7, and the specific process is described as follows:

(1) The threshold of the average of the height of the building is learned based on the training samples. If the average of the height is less than the threshold, the building is determined to be totally collapsed. Otherwise, it belongs to other types.

(2) Among other types, the threshold of the variance of the height is learned. If the variance of the height is greater than the threshold, the building is determined to be partially collapsed. Otherwise, it belongs to not collapsed buildings.

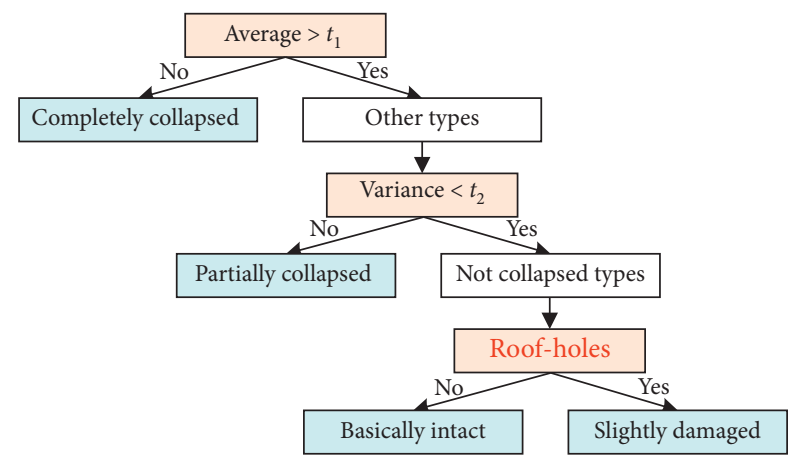

Figure 7: Decision tree for building damage classification.

(3) For the not collapsed buildings, it is difficult to make a distinction between the slightly damaged buildings and basically intact buildings based only on the heights in the $3 \mathrm{D}$ model reconstructed by point clouds. In order to detect slightly damaged buildings, the roof-holes detected in previous subsection are employed to cooperate with the heights of the buildings. The detected roof-holes overlap the boundary of the buildings; if the interior of the building boundary contains the roof-holes, the building can be taken as slightly damaged building; otherwise, it belongs to basically intact buildings.

\section{Result}

4.1. Image Registration. In order to obtain accurate building damage information, it is necessary to match the extracted building boundary with the postearthquake UAV images. Therefore, the preearthquake VHR satellite images and the postearthquake UAV images will be performed with image registration.

To ensure the accuracy of image registration, we use the way of manual registration. For the study area of Zhoujiawan village, a total of 320 homonymy points matched the preearthquake QuickBird image with the postearthquake orthomosaic UAV image. Similarly, in terms of Yuxi village, a total of 120 homonymy points matched the preearthquake Pléiades image with the postearthquake orthomosaic UAV image. Since the ranges of the two study areas are different, the number of homonymy points is different. For example, the orthomosaic image of Zhoujiawan village covers about $1.33 \mathrm{~km}^{2}$, but the residential regions only account for approximately $20 \%$ of the whole image, and most of the homonymy points focus on the residential regions. Therefore, it is believed that it is accurate for the matching of preearthquake satellite images and the postearthquake UAV images.

4.2. Experimental Results. Three experiments are conducted in this section, and they are building extraction, roof-hole detection, and building damage classification, respectively.

4.2.1. Building Extraction. Two preearthquake VHR satellite images, that is, QuickBird and Pléiades images, covering two study areas were used in the experiment of building 
extraction. In this experiment, we compared the building results extracted from a single image with those from two heterogeneous satellite images. Two compared experiments were designed for the QuickBird image in Zhoujiawan village. In the first experiment, only the QuickBird image was used to extract buildings. As a comparison, two satellite images from different sensors (i.e., QuickBird and Pléiades) were used as inputs for the model in the second experiment. The model parameters learned from the Pléiades image were directly applied to the QuickBird image for building extraction. The results show that building results extracted from one single image were very close to the results from two heterogeneous satellite images, as shown in Figure 8. Meanwhile, Table 1 gives the quantitative evaluation of the building results of the two ways, and the building results extracted from a single image were $0.2 \%$ higher than those from two different images in terms of recall and precision. The difference in accuracy is very small. Therefore, we conclude that the proposed method has the ability to simultaneously extract buildings from multiple heterogeneous and noncalibrated VHR satellite images. Like the QuickBird image, we also did the same comparative experiments on Pléiades image, and the results were consistent with QuickBird image.

4.2.2. Roof-Hole Detection. As described in Section 3.3.1, roof-holes only existed in the slightly damaged buildings. After comparing the postearthquake UAV images of the two study areas, we found that Zhoujiawan village was located in IX-degree intensity zone, and the buildings were seriously damaged, and the roof-holes in the buildings are not common. Therefore, the postearthquake UAV images of Yuxi village were used to conducted the experiment of the roof-hole detection.

The results of roof-hole detection using the proposed method and its ground truth are given in Figure 9. It is noticed that the proposed method can distinguish the roofholes from the shadows. Although roof-holes and shadows have higher similarity in spectra, they are different in height feature. In the proposed method, the model could describe the hierarchical clustering process using UAV images with joint color and height features. Therefore, the height is a very important cue to make a distinction between roof-holes and shadows in the proposed method. In addition, the detection result of the proposed method seems to be more compact. In other words, the result of the proposed method seems to have object-oriented property. Specifically, a group of neighbor pixels called a segmentation here is regarded as a sample in the proposed method. More details on the experiments of roof-hole detection can be found in previous study [23].

4.2.3. Building Damage Classification. According to the geometric shapes of the buildings in the $3 \mathrm{D}$ point clouds, the buildings in the two study areas are manually classified into three types: "herringbone," "convex," and "rectangle," as shown in Figure 10. In the type of "herringbone" buildings, the obvious strips exist in the whole roof of the buildings. It is worth noting that the slightly damaged buildings only occur in this type of buildings. For the "convex" buildings, there is no strip in the roofs, and the distribution of brightness is regular. It is interesting that there is a rectangle chimney on the roof, so that the whole building looks like "convex" in the 3D model. In terms of "rectangle" buildings, the distribution of brightness of the roof is regular, and it is the most common type in the buildings. It needs to notice that all of the three types of buildings exist in the study area of Yuxi village. However, there are only "herringbone" and "rectangle" buildings in Zhoujiawan village, and no "convex" buildings are found.

In the experiments, a total of 702 buildings exist in the two study areas, that is, 125 buildings in Yuxi village and 577 buildings in Zhoujiawan village. Of all the samples, 250 samples are used for model training, and others are used for accuracy analysis of classification results. Since the splitting attributes have been predetermined in this decision tree, the model only needs to train splitting thresholds for each attribute. In the decision tree, the attribute of the average of the height is firstly used, and its threshold is 3 meters. Both the two study areas are located in the rural regions, where all of buildings are of one floor. Therefore, if the average height of one building is less than 3 meters, the building is labeled as completely collapsed. Otherwise, it would be other types of buildings.

For the buildings to be determined, the attribute of the variance of the height is secondly used. Since the types of the buildings are different, such as "herringbone," "convex," and "rectangle" buildings, the variance thresholds for different types of buildings to determine partially collapsed buildings are different, which are shown in Figure 11. For the "herringbone" and "rectangle" buildings, there is no obvious difference in terms of the variance. Therefore, they share the same variance threshold. It means that if the variance of one building is more than 2, it is determined to be partially collapsed. Otherwise, it belongs to not collapsed buildings. However, in terms of "convex" buildings, since there is a rectangle chimney on the roof, there exist two forms of partial collapse: (1) the chimney is collapsed and (2) part of the buildings is collapsed. In the experiments, if the chimney on the roof is destroyed, the variance of the height is less than 2 . When the variance is greater than 5 , it implies that the second situation has occurred; that is, part of the building is collapsed. Therefore, if the variance is less than 2 or greater than 5 , the building is determined to be partially collapsed. Otherwise, it belongs to not collapsed buildings.

For the not collapsed buildings, the roof-holes detected in previous section are employed to cooperate with the height attribute. The detected roof-holes overlap the boundary of the buildings; if the interior of one building contains the roof-holes, the building can be taken as slightly damaged building; otherwise, it belongs to basically intact buildings.

Figure 12 shows the results of building damage classification in Yuxi and Zhoujiawan villages, respectively. The corresponding statistical results of the two study areas are given in Table 2. For Yuxi village in Ya'an earthquake, the total of 125 buildings are determined to be 46 basically intact 


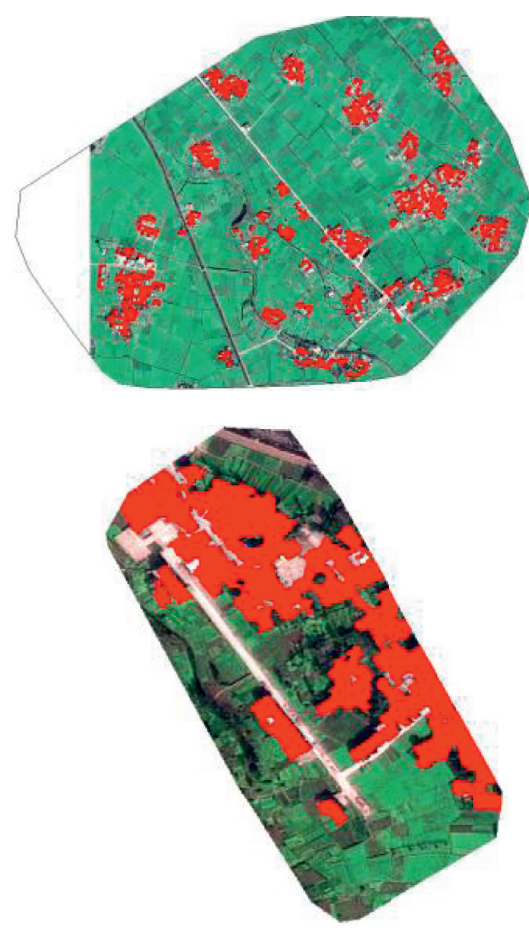

(a)
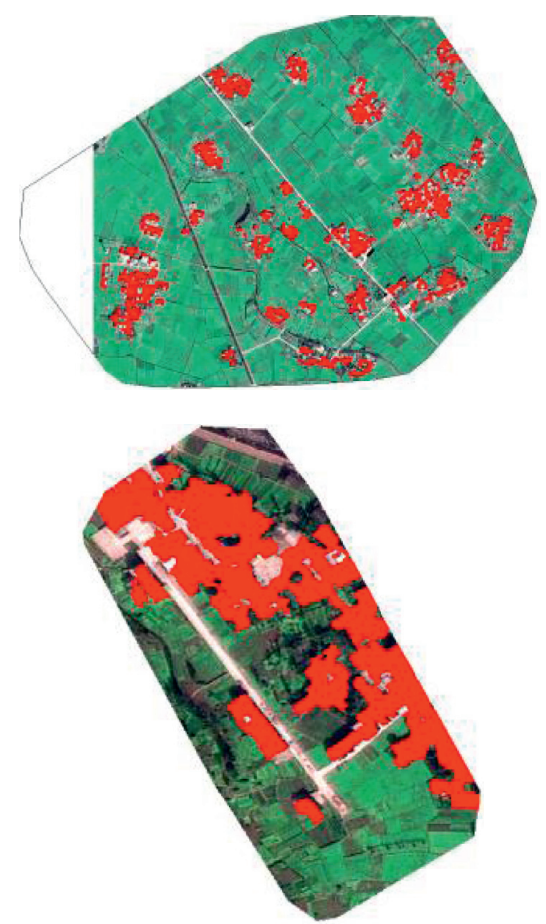

(b)
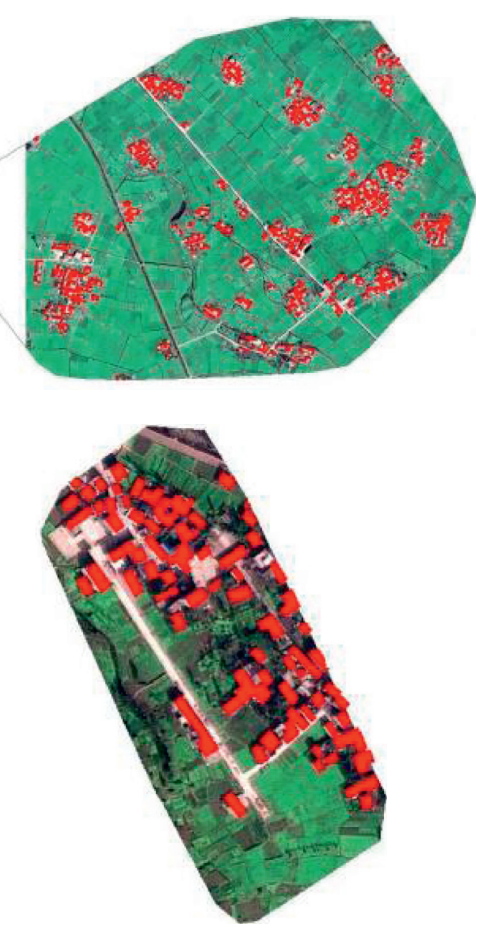

(c)

FIGURE 8: Comparison of the proposed method with the ground truth. (a) Red polygons represent the results detected by one single image. (b) The results detected by two different images. (c) The ground truth.

TABLE 1: Quantitative evaluation of the building results from a single image and two different images.

\begin{tabular}{lcc}
\hline Input images & Recall (\%) & Precision (\%) \\
\hline Only QuickBird image & 86.39 & 75.62 \\
Two different images (for QuickBird image) & 86.19 & 75.36 \\
Only Pléiades image & 80.73 & 72.73 \\
Two different images (for Pléiades image) & 80.49 & 72.42 \\
\hline
\end{tabular}

buildings, 43 slightly damaged buildings, 33 partially collapsed buildings, and 3 completely collapsed buildings, which are consistent with the result of visual interpretation. There are a total of 581 buildings in Zhoujiawan village, and 4 buildings are not determined due to the lack of point clouds. Therefore, 577 buildings are determined to be 214 basically intact buildings, 171 partially collapsed buildings, and 164 completely collapsed buildings.

\section{Discussion}

Due to the fact that the roof-holes can be detected in Yuxi village of Ya'an earthquake, building damage classification in Yuxi village is classified into four grades, basically intact, slightly damaged, partially collapsed, and completely collapsed buildings, as shown in Figure 12(a). As a comparison, it is noticed that Zhoujiawan village is located in the junction of IX-degree and X-degree intensity zone, and the buildings are seriously damaged in Wenchuan earthquake, and the roof-holes are not been detected in this study area. Therefore, building damage classification in Zhoujiawan village is classified into only three grades, basically intact, partially collapsed, completely collapsed buildings, with no slightly damaged buildings, as shown in Figure 12(b).

In addition, the results in Zhoujiawan village have some differences with the result of visual interpretation, because the UAV images of Zhoujiawan village were obtained one year after Wenchuan earthquake, and several completely collapsed buildings were replaced by new temporary buildings. This leads to the fact that some collapsed buildings were misjudged as partially collapsed or not collapsed buildings. In addition, there exist some new buildings built on vacant lands in the postearthquake image, such as the external walls of buildings. But the vector boundaries of buildings are obtained from the preearthquake satellite images. Therefore, the new buildings shown in the postearthquake UAV image have not been considered here.

As a conclusion, a decision-tree-based approach is presented to classify the type of building damage by using pre- and postearthquakes multiple-source remote sensing in this paper. Building boundary is firstly extracted from preearthquake heterogeneous VHR satellite images, and then building damage is detected and classified into four types using decision tree algorithm from postearthquake 




(a)

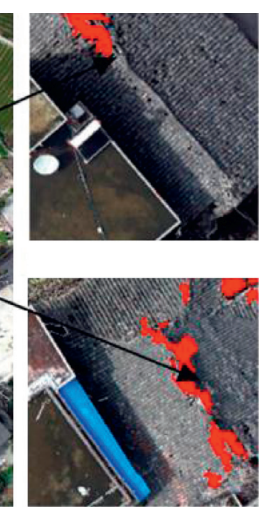

(a)

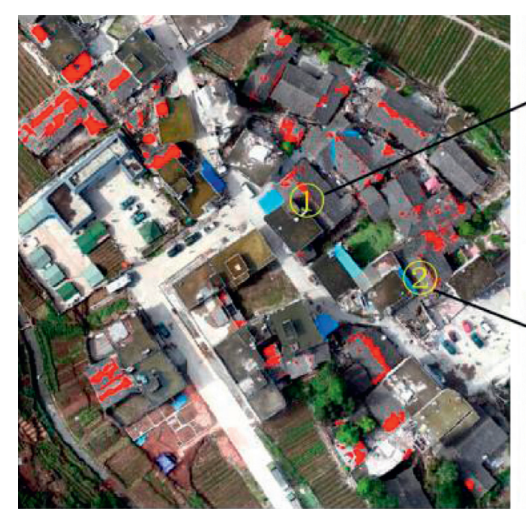

(b)

FIgURE 9: Comparison of the proposed method with the ground truth. (a) Red polygons represent the results detected using the proposed method. (b) The ground truth.
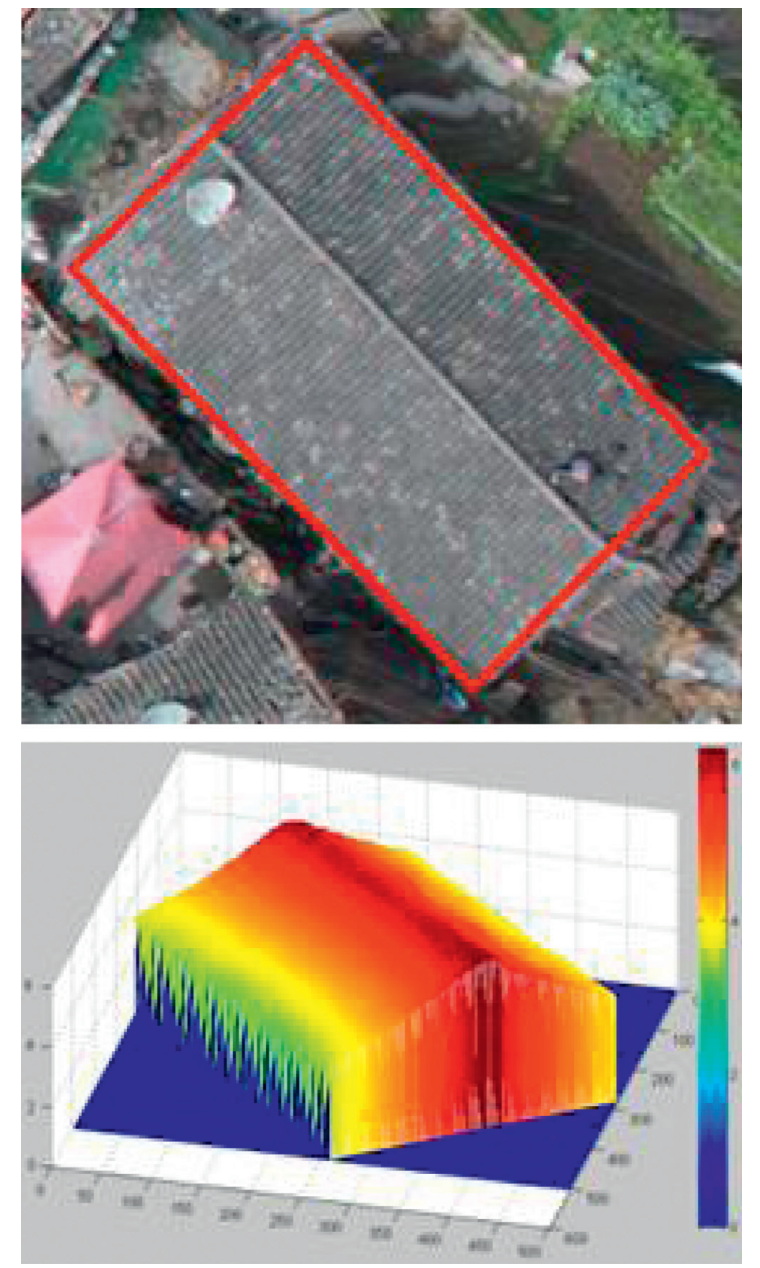

(a)
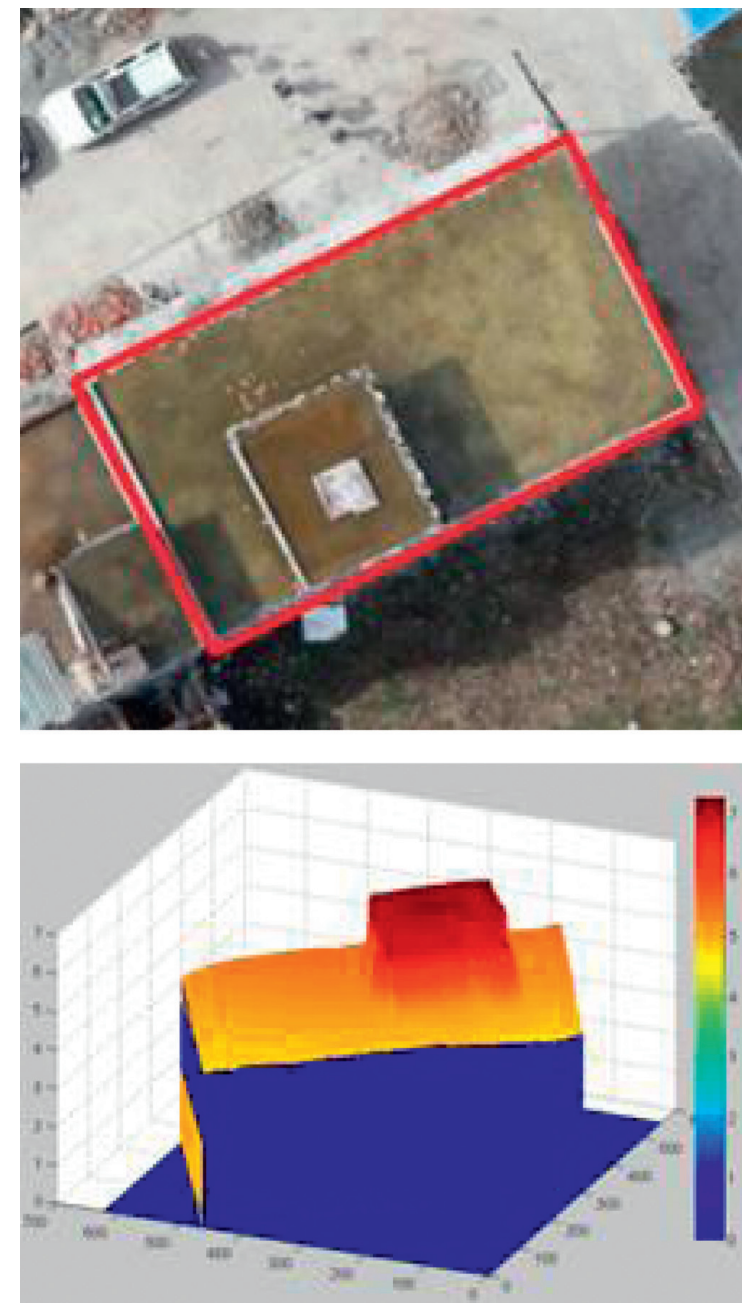

(b)

Figure 10: Continued. 

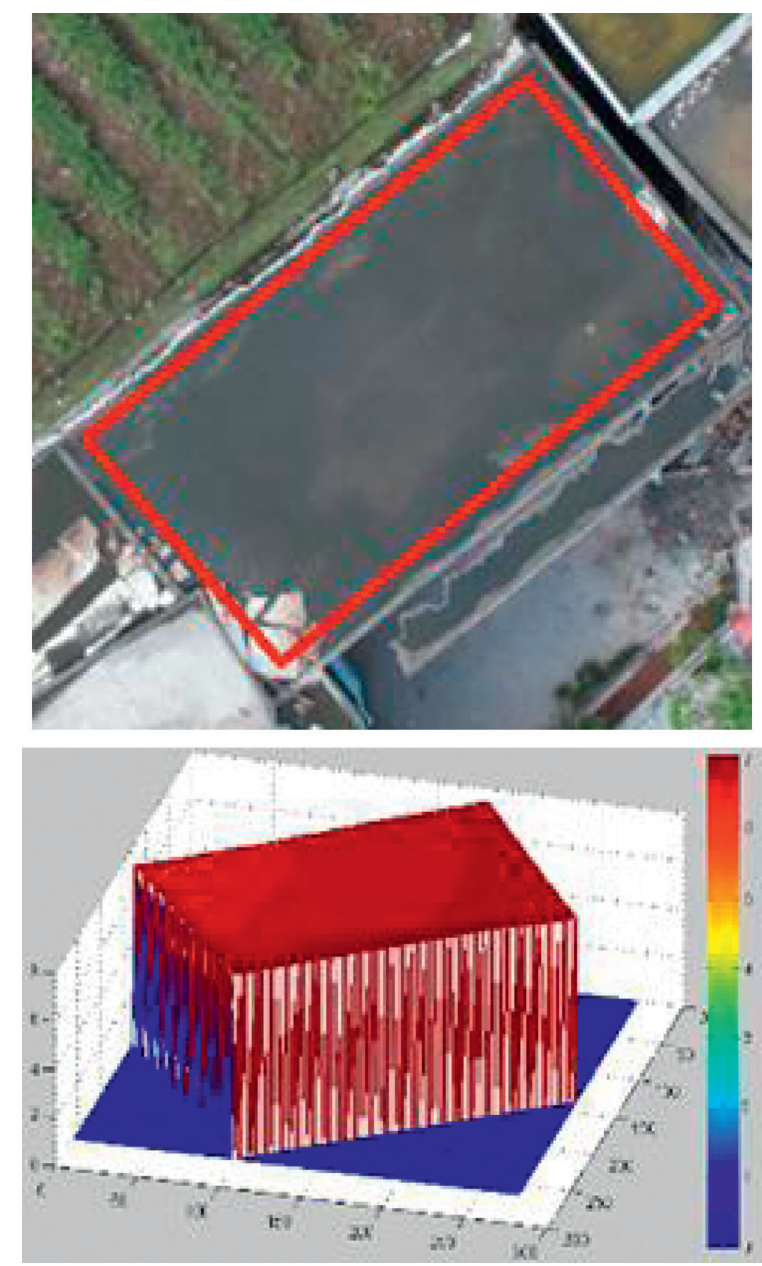

(c)

Figure 10: Different types of buildings in two study areas. (a) Herringbone type. (b) Convex type. (c) Rectangular type.

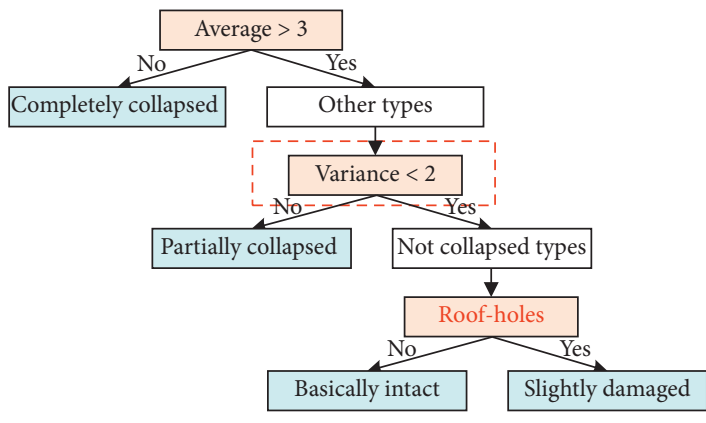

(a)

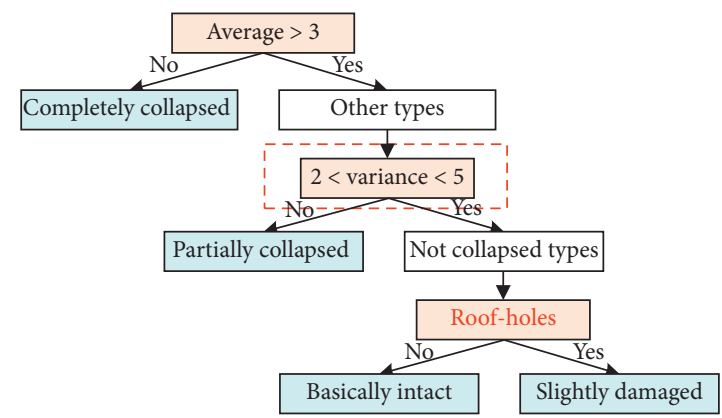

(b)

FIGURE 11: Different decision trees for partially collapsed buildings in different types of buildings: (a) decision tree for "herringbone" and "rectangle" buildings and (b) decision tree for "convex" buildings.

UAV images basically intact buildings, slightly damaged buildings, partially collapsed buildings, and completely collapsed buildings. In particular, slightly damaged buildings are determined by the detected roof-holes using joint color and height features. In order to verify the proposed method, the preearthquake QuickBird and Pléiades images covering two study areas are experimented to extract buildings, and the corresponding postearthquake UAV images are used to detect building damage classification, respectively. Experimental results in the two study areas are consistent with those of visual interpretation, and the results show the validity and practicability of the proposed method. 


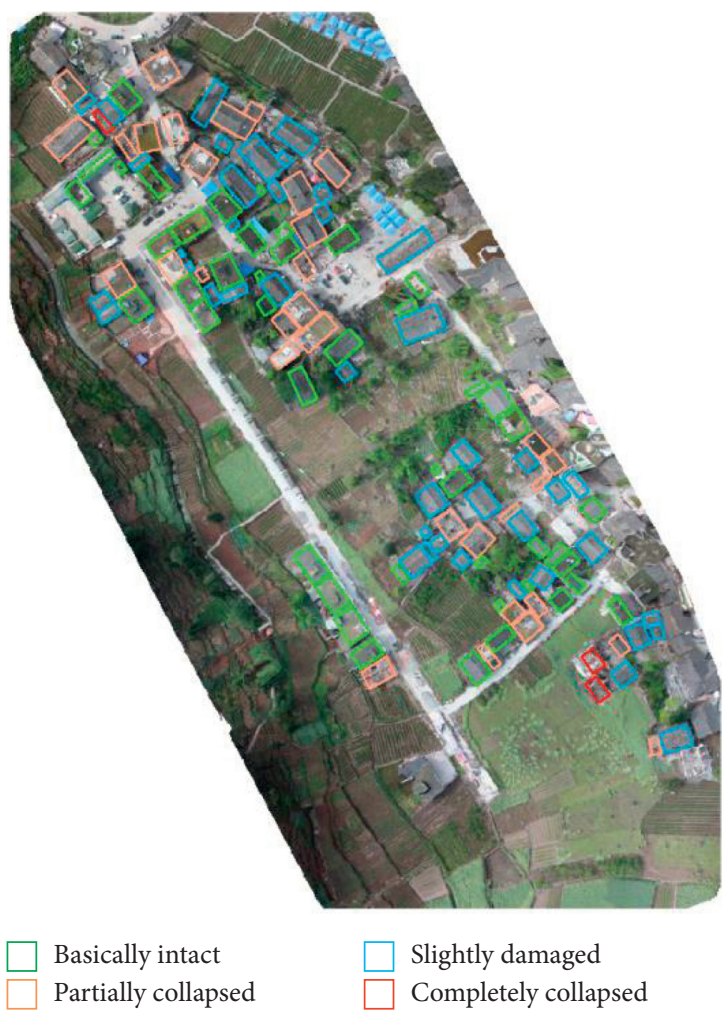

(a)
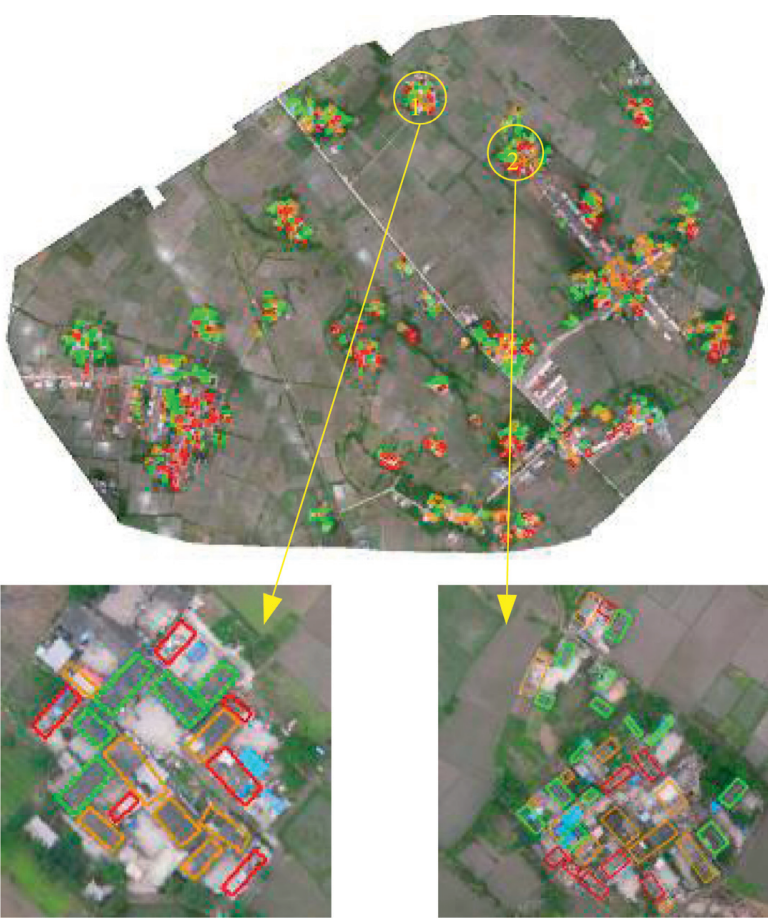

Basically intact

Partially collapsed

Completely collapsed

(b)

Figure 12: Results of building damage classification in two study areas. (a) Results of building damage in Yuxi village. (b) Results of building damage in Zhoujiawan village.

TABLE 2: Quantitative analysis of the results of the building damage classification.

\begin{tabular}{lcccc}
\hline Study areas & Types of building damage & Ground truth & Correct number & Wrong number \\
\hline \multirow{4}{*}{ Yuxi village } & Basically intact & 46 & 46 & 0 \\
& Slightly damaged & 43 & 43 & 0 \\
& Partially collapsed & 33 & 33 & 0 \\
\hline \multirow{3}{*}{ Zhoujiawan village } & Completely collapsed & 3 & 3 & 0 \\
& Basically intact & 225 & 214 & 11 \\
& Partially collapsed & 179 & 171 & 8 \\
\end{tabular}

\section{Data Availability}

The original preearthquake satellite images and the postearthquake UAV images used to support the findings of this study are available from the authors upon request.

\section{Conflicts of Interest}

The authors declare that they have no conflicts of interest.

\section{Acknowledgments}

This work was partly supported by the National Natural Science Foundation of China (no. 41801240), the Natural Science Foundation of Hebei (no. D2019205067), the Hebei Education Department (no. QN2018133), the Doctoral
Foundation of Hebei Normal University (no. L2018B19), and the National Key R\&D Program of China under Grant no. 2017 YFB0504104.

\section{References}

[1] G. Grunthal, "European macroseismic scale 1998," Cahiers du Centre Europeen de Geodynamique et de Seismologie, vol. 15, pp. 1-99, 1998.

[2] L. Dong and J. Shan, "A comprehensive review of earthquakeinduced building damage detection with remote sensing techniques," ISPRS Journal of Photogrammetry and Remote Sensing, vol. 84, pp. 85-99, 2013.

[3] P. Gamba, F. Dell'Acqua, and G. Trianni, "Rapid damage detection in the Bam area using multitemporal SAR and exploiting ancillary data," IEEE Transactions on Geoscience and Remote Sensing, vol. 45, no. 6, pp. 1582-1589, 2007. 
[4] C. Schweier and M. Markus, "Classification of collapsed buildings for fast damage and loss assessment," Bulletin of Earthquake Engineering, vol. 4, no. 2, pp. 177-192, 2006.

[5] K. Saito, R. J. S. Spence, C. Going, and M. Markus, "Using high-resolution satellite images for post-earthquake building damage assessment: a study following the 26 january 2001 Gujarat earthquake," Earthquake Spectra, vol. 20, no. 1, pp. 145-169, 2004.

[6] L. Gusella, B. J. Adams, G. C. Bitelli, K. Huyck, and A. Mognol, "Object-oriented image understanding and postearthquake damage assessment for the 2003 Bam, Iran, earthquake," Earthquake Spectra, vol. 21, no. S1, pp. 225-238, 2005.

[7] P. J. Li, H. Q. Xu, and J. C. Guo, "Urban building damage detection from very high resolution imagery using OCSVM and spatial features," International Journal of Remote Sensing, vol. 31, no. 13, pp. 3393-3409, 2010.

[8] J. H. Liu, X. J. Shan, and J. Y. Yin, “Automatic recognition of damaged town buildings caused by earthquake using remote sensing information: taking the 2001 BHUJ, India Earthquake and the 1976 Tangshan, China Earthquake as examples," Acta Seismologica Sinica, vol. 17, no. 6, pp. 623-632, 2004.

[9] P. Gamba, F. Dell Acqua, and L. Odasso, "Object-oriented building damage analysis in VHR optical satellite images of the 2004 tsunami over Kalutara, Sri Lanka," in Proceedings of the Urban Remote Sensing Joint Event, Paris, France, April 2007.

[10] X. Tong, Z. Hong, S. Liu et al., "Building-damage detection using pre- and post-seismic high-resolution satellite stereo imagery: a case study of the May 2008 Wenchuan earthquake," ISPRS Journal of Photogrammetry and Remote Sensing, vol. 68, no. 2, pp. 13-27, 2012.

[11] A. L. Chesnel, R. Binet, and L. Wald, "Object oriented assessment of damage due tonatural disaster using very high resolution images," in Proceedings of the IEEE International Geoscience and Remote Sensing Symposium, pp. 3736-3739, Barcelona, Spain, July 2007.

[12] Y. Iwasaki and F. Yamazaki, "Detection of building collapse from the shadow lengths in optical satellite images," in Proceedings of 32nd Asian Conference on Remote Sensing, Taipei, Taiwan, October 2011.

[13] F. Yamazaki, T. T. Vu, and M. Matsuoka, "Context-based detection of post-disaster damaged buildings in urban areas from satellite images," in Proceedings of the Urban Remote Sensing Joint Event, Paris, France, April 2007.

[14] H. Lu, Y. S. Li, J. He, Q. Chen, and Z. P. Ren, “An automatic mosaic method in unmanned aerial vehicle images based on feature points," Geography and Geo-Information Science, vol. 26, no. 5, pp. 16-19, 2010.

[15] B. Wang and W. F. Wang, "Unmanned aerial vehicle image mosaic algorithm based on local gray fitting," Journal of China University of Petroleum, vol. 33, no. 2, pp. 169-173, 2009.

[16] H. Miura, S. Modorikawa, and S. H. Chen, "Texture characteristics of highresolution satellite images in damaged areas of the 2010 Haiti Earthquake," in Proceedings of 9th International Workshop on Remote Sensing for Disaster Response, vol. 1-9, Stanford, CA, USA, September 2011.

[17] M. Chini, F. R. Cinti, and S. Stramondo, "Co-seismic surface effects from very high resolution panchromatic images: the case of the 2005 Kashmir (Pakistan) earthquake," Natural Hazards and Earth System Sciences, vol. 11, no. 3, pp. 931-943, 2011.

[18] S. Li, H. Tang, X. Huang, T. Mao, and X. Niu, "Automated detection of buildings from heterogeneous VHR satellite images for rapid response to natural disasters," Remote Sensing, vol. 9, no. 11, p. 1177, 2017.

[19] X. Hou and L. Zhang, "Saliency detection: a spectral residual approach," in Proceedings of the Computer Vision and Pattern Recognition, pp. 17-22, Minneapolis, MA, USA, June 2007.

[20] X. Huang and L. Zhang, "A multidirectional and multiscale morphological index for automatic building extraction from multispectral GeoEye-1 imagery," Photogrammetric Engineering \& Remote Sensing, vol. 77, no. 7, pp. 721-732, 2011.

[21] T. Mao, H. Tang, J. Wu, W. Jiang, S. He, and Y. Shu, "A generalized metaphor of Chinese restaurant franchise to fusing both panchromatic and multispectral images for unsupervised classification," IEEE Transactions on Geoscience and Remote Sensing, vol. 54, no. 8, pp. 4594-4604, 2016.

[22] S. Li and H. Tang, "Building damage extraction triggered by earthquake using the UAV imagery," in Proceedings of the International Society For Photogrammetry And Remote Sensing, Beijing, China, 2018.

[23] C. Strecha and O. Kung, "Pix4UAV software, open source geospatial foundation," http://www.pix4d.com.

[24] S. Li, H. Tang, S. He et al., "Unsupervised detection of earthquake-triggered roof-holes from UAV images using joint color and shape features," IEEE Geoscience and Remote Sensing Letters, vol. 12, no. 9, pp. 1823-1827, 2015.

[25] Z. H. Zhou, Machine Learning, Tsinghua University Press, Beijing, China, 2016. 